\title{
Investigation of first mirror heating for the collective Thomson scattering diagnostic in
} ITER

Salewski, Mirko; Meo, Fernando; Bindslev, Henrik; Furtula, Vedran; Korsholm, Søren Bang; Lauritzen, Bent; Leipold, Frank; Michelsen, Poul; Nielsen, Stefan Kragh; Nonbøl, Erik

Published in:

Review of Scientific Instruments

Link to article, DOI:

$10.1063 / 1.2956961$

Publication date:

2008

Document Version

Publisher's PDF, also known as Version of record

Link back to DTU Orbit

Citation (APA):

Salewski, M., Meo, F., Bindslev, H., Furtula, V., Korsholm, S. B., Lauritzen, B., Leipold, F., Michelsen, P., Nielsen, S. K., \& Nonbøl, E. (2008). Investigation of first mirror heating for the collective Thomson scattering diagnostic in ITER. Review of Scientific Instruments, 79(10), 10E729. https://doi.org/10.1063/1.2956961

\section{General rights}

Copyright and moral rights for the publications made accessible in the public portal are retained by the authors and/or other copyright owners and it is a condition of accessing publications that users recognise and abide by the legal requirements associated with these rights.

- Users may download and print one copy of any publication from the public portal for the purpose of private study or research.

- You may not further distribute the material or use it for any profit-making activity or commercial gain

- You may freely distribute the URL identifying the publication in the public portal 


\title{
Investigation of first mirror heating for the collective Thomson scattering diagnostic in ITER ${ }^{a)}$
}

\author{
M. Salewski, F. Meo, H. Bindslev, V. Furtula, S. B. Korsholm, B. Lauritzen, F. Leipold, \\ P. K. Michelsen, S. K. Nielsen, and E. Nonbøl \\ Association EURATOM-Risø National Laboratory for Sustainable Energy, Technical University of Denmark, \\ Roskilde DK-4000, Denmark
}

(Presented 13 May 2008; received 9 May 2008; accepted 28 May 2008;

published online 31 October 2008)

\begin{abstract}
Collective Thomson scattering (CTS) has the capabilities to measure phase space densities of fast ion populations in ITER resolved in configuration space, in velocity space, and in time. In the CTS system proposed for ITER, probing radiation at $60 \mathrm{GHz}$ generated by two $1 \mathrm{MW}$ gyrotrons is scattered in the plasma and collected by arrays of receivers. The transmission lines from the gyrotrons to the plasma and from the plasma to the receivers contain several quasioptical mirrors among other components. These are designed to produce astigmatic beam patterns in the plasma where the beam shapes will have a direct impact on the signal strength of the diagnostic, the spatial resolution, and the robustness of probe and receiver beam overlap against density excursions. The first mirror has a line of sight to the plasma and is thus exposed to severe neutron streaming. The present neutronics and thermomechanical modeling of a first mirror on the high field side indicates that the mirror curvature may warp due to heating. This may alter the beam quality, and therefore, thermal effects have to be accounted for during the design of the mirror. The modeling further demonstrates that thin mirrors are superior to thick mirrors from a thermomechanical point of view. (c) 2008 American Institute of Physics. [DOI: 10.1063/1.2956961]
\end{abstract}

\section{INTRODUCTION}

Collective Thomson scattering (CTS) is a multifaceted diagnostic with which it is possible to measure dynamics of phase space densities of confined fast ion populations. Fast ion CTS has been demonstrated at JET ${ }^{1}$ and TEXTOR ${ }^{2}$ and is currently being commissioned at ASDEX Upgrade. ${ }^{3}$ ITER will contain a burning plasma with a significant heating contribution due to fusion born $\alpha$-particles. The tokamak will operate at larger Lawson products than those achieved in current tokamaks with the consequence that neutron and heat fluxes on instruments with plasma facing components are much larger than on comparable, currently operational devices. The proposed CTS system for ITER is described in detail in Refs. 4 and 5. It utilizes millimeter waves at $60 \mathrm{GHz}$ which are generated by gyrotrons with a power level of $1 \mathrm{MW}$ each. These are launched into the plasma where they interact with fluctuations in the plasma in scattering processes. The spectral power density of scattered radiation leaving the plasma contains information about the fluctuations, and various plasma parameters can therefore be inferred, among these the one dimensional fast ion velocity distribution. The resolution of the proposed diagnostic is $40 \mathrm{~ms}$ in time and $a / 10$ in space (where $a$ is the minor radius) with at least 16 velocity bins for the given target accuracy such that the ITER measurement requirements for fusion $\alpha$ diagnostic are fulfilled. ${ }^{6}$ The proposed fast ion CTS

\footnotetext{
a) Contributed paper, published as part of the Proceedings of the 17th Topical Conference on High-Temperature Plasma Diagnostics, Albuquerque, New Mexico, May 2008.
}

diagnostic consists of two separate systems. Each system has its own rf launcher and separate set of detectors, capable of measuring fast ion distributions near parallel and near perpendicular to the magnetic field, respectively. The near perpendicular velocity components can be found by measuring backscattered radiation received with an antenna on the low field side whereas forward-scattered radiation is collected by an antenna located on the high field side (HFS) to obtain the near parallel velocities. Results of neutronics and thermomechanical modeling of the first mirror of the HFS antenna are discussed here.

A common feature of many diagnostic systems relying on collecting electromagnetic radiation in ITER is the necessity to design a first mirror robust against irradiation originating from the fusion plasma. ${ }^{7,8}$ For the HFS CTS system, the photon and neutron fluxes along the direct line of sight from the plasma are further enhanced by the need to cut out shielding blanket material due to space limitations on the HFS of the tokamak: There is not enough room to place the receiver mirrors behind a blanket of nominal thickness. For first mirrors designed for wavelengths in the optical range, deposition on the mirror surface and erosion are main concerns among others. ${ }^{9}$ This set of current research objectives is less relevant for CTS first mirrors since the wavelength of millimeter waves is much larger than the atomic scales and the CTS instrument is therefore robust against such smallscale effects. The downside of larger wavelengths is that the apertures typically need to be much larger, enhancing the heating power by direct irradiation from the plasma. This challenge is shared by other diagnostics exploiting waves in 
the microwave range, such as reflectometry or electron cyclotron emission diagnostic. ${ }^{10}$ First mirrors in gyrotron transmission lines as for the CTS probe beam or electron cyclotron heating or current drive additionally have an excessive heat load due to the incident wave beam. ${ }^{11,12}$ Large thermal stresses may develop in the first mirrors which have to be designed so as to avoid the regime of plastic deformation. Second, due to warping of the mirror surface and displacement of the mirror due to thermal strain or electromagnetic forces, the beam quality may be compromised having direct impact on the shape of the astigmatic beams in the plasma. This in turn may degrade the diagnostic performance, namely, the CTS signal, the spatial resolution, and the robustness of beam overlap against density excursions.

The present modeling of neutronics and thermoelastic stresses indicates that the mirror curvature may change due to thermal strain. Various mirror designs are being compared in terms of temperature distribution, the displacement, and thermal strain (after the von Mises failure hypothesis). It is found that the mirrors should be thin to avoid large temperature differences and volumetric heating. However, the lower bound on the mirror thickness is given by unfavorable thermal footprints of backside features for too thin mirrors and by the technical difficulty to manufacture and integrate such mirrors including a cooling system if required.

\section{GOVERNING EQUATIONS, NUMERICAL METHODS, AND BOUNDARY CONDITIONS}

We model the interaction physics of materials with neutrons generated at $14 \mathrm{MeV}$ from the $D-T$ fusion process and the $\gamma$ 's from the $(n, \gamma)$ processes in Monte Carlo simulations with the MCNP-5 code. ${ }^{13}$ We use as the geometry a simplified version of the ITER-FEAT model which is being used for full three dimensional (3D) neutronics calculations for ITER systems. We find that the volumetric heating rate is approximately constant over the mirror penetration depth at $665 \mathrm{~kW} / \mathrm{m}^{3}$ for the given geometry (assuming an aperture width of $30 \mathrm{~mm}$ through the blanket modules ${ }^{5}$ ).

The steady-state heat equation and Navier's continuum equations have been solved in $3 \mathrm{D}$ by the finite element method applying the commercially available software ANSYS for this purpose. The heat equation contains a source term accounting for the volumetric heating due to $\gamma$ 's and neutrons described above. Since the mirror deformation is small, the stress-strain problem can be decoupled from the temperature problem, facilitating a sequential solution. The partial integro-differential equations are discretized on irregular meshes composed of ten-node tetrahedral elements. Up to 500000 nodes are used to describe the mirror. The nonlinear set of equations is solved iteratively with a conjugate gradient solver. The mirror material is assumed to be isotropic stainless steel (SS316). The material properties are taken from the ITER Material Properties Handbook for a temperature of $200{ }^{\circ} \mathrm{C}$. ${ }^{14}$ An overview of the geometry of a mirror with a thickness of $10 \mathrm{~mm}$ is illustrated in Fig. 1 (colored by the temperature distribution for a base line case as described in Sec. IV). The mirror design in this study has a support arm on the rear side, allowing for free thermal expansion. In this

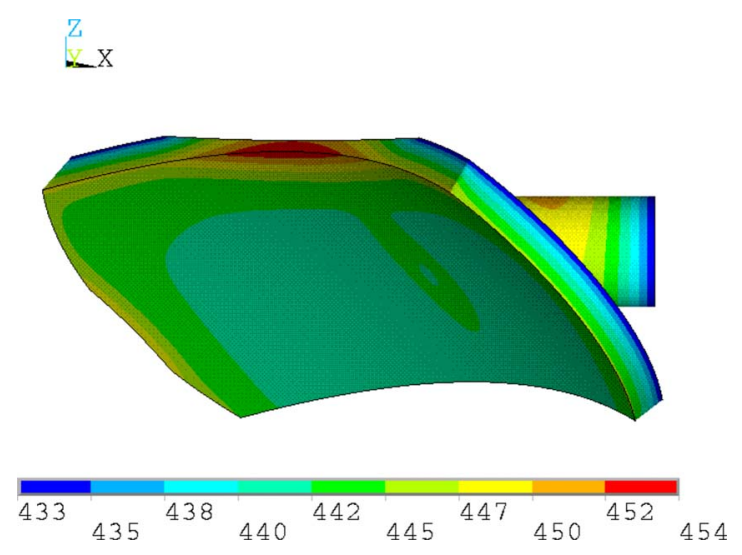

FIG. 1. (Color online) Temperature distribution (in kelvin) on HFS first mirror with $10 \mathrm{~mm}$ thickness under base line conditions.

study, several mirror thicknesses from 5 to $30 \mathrm{~mm}$ have been computed. However, geometric constraints due to the enclosure hosting the mirror require that several edges are cut so as to fit the mirror into the small available space.

We assume a plasma with $500 \mathrm{MW}$ fusion power. In addition to the $\gamma$ 's and neutrons, the mirror is exposed to direct irradiation from the plasma, originating mostly from bremsstrahlung ( $\sim 40 \mathrm{MW})$, cyclotron radiation, and line radiation. Particle fluxes constitute an additional heat load to be considered. The wavelength of the bremsstrahlung lies in the soft x-ray range which is absorbed in the first few millimeters of the mirror. This radiation is supposed to be diffused and fully absorbed (no reflection). We model this contribution together with the heat load due to particle flux and ultraviolet radiation as surface heat load. Electron cyclotron radiation lies in the microwave range, and hence these contributions are supposed to be fully reflected (or negligible altogether). The first mirror is recessed behind the blanket viewing the plasma through a horizontal gap between the blanket modules, and so the heat load is reduced by a view factor of 0.1 compared to the heat load on the first wall of the tokamak. The curved mirror surface is assumed to have an angle of $45^{\circ}$ to the propagation direction, further reducing the heat flux. The total cooling demand can be estimated to be up to $1000 \mathrm{~W}$, depending on the mirror thickness, for these plasma parameters, which is to be transferred via radiation, conduction, and active cooling with water if needed. As the first mirror is hotter than the inner walls of the enclosure supporting it, it is in any case radiation cooled by heat transfer to the surroundings with a temperature of $473 \mathrm{~K}$. The heat flux is modeled by the Stefan-Boltzmann law assuming gray body radiation with an emissivity of 0.5 . A second heat sink is given by the support arm which sustains conduction heat flux to the actively cooled wall which is maintained at a constant temperature of $433 \mathrm{~K}$. Optionally, active cooling of the mirror backside is under consideration and if so will be maintained at $433 \mathrm{~K}$ as well.

\section{UNCERTAINTIES AND LIMITATIONS}

The discretization and iteration errors for the temperatures and the deformations are converged to an accuracy of less than $0.1 \%$ which is far more accurate than limits im- 
posed by uncertain boundary conditions (e.g., the fusion power for which we assume the nominal value of $500 \mathrm{MW}$ ) and material properties (e.g., emissivity). The volumetric heat source term is computed in the Monte Carlo simulation to a convergence accuracy of $2 \%$, although the model geometry is simplified, introducing additional modeling uncertainties. We model this heat source term as a constant over the mirror volume whereas it decreases slightly with penetration depth, giving an error of about $10 \%$ in the source term. As the direct plasma radiation depends, for example, on impurity levels and the particle flux on confinement, the surface heat load is not accurately known even for a nominal fusion plasma scenario and is therefore varied in a sensitivity study. Further modeling uncertainties stems from the estimation of the view factor, the angle of the surface, and the amount of reflected radiation from the plasma as well as for the heat exchange with the surrounding objects. The amount of reflected radiation depends on the frequency of the radiation and this has not been included in the modeling. The assumed temperature of actively cooled surfaces depends on the design of the cooling system, e.g., there can be nonuniformities in temperature. The governing equations contain also material properties which are assumed constant in the present study. Due to the strong nonlinearity of the StefanBoltzmann law, the error is difficult to asses without parametric variations in this respect.

For the solution of the strain problem, we limit our study to thermal strains and defer strains due to electromagnetic forces to future studies. Uncertainties in the thermal strains then originate from the previously computed temperature gradients discussed above. Second, the base of the mirror support arm is assumed to have zero displacement, i.e., it is assumed fixed in space. This is of course not true as the entire structure changes temperature as well. This is irrelevant for computation of the von Mises stresses but is relevant for the computation of the absolute displacement of the mirror surface which redirects the beam. The material properties in Navier's continuum equations are also temperature dependent which has been neglected. Several topics mentioned above will be included in future modelling efforts.

\section{RESULTS AND DISCUSSION}

As mentioned in Sec. II, Fig. 1 illustrates the temperature distribution on the first mirror for the base line heat load scenario (heat flux: $16 \mathrm{~kW} / \mathrm{m}^{2}$, emissivity: 0.5 ). Active water cooling is assumed in this case. The cooling system is assumed to be mounted on the backside of the mirror, maintaining the backside of the mirror at $433 \mathrm{~K}$. The temperature difference between front- and backside is below $5 \%$ yielding acceptable thermal stresses.

Figure 2 summarizes the results of a parametric variation of the surface heat load on the first mirror: The maximum temperature is plotted versus the surface heat flux. The largest flux considered in this graph is $16 \mathrm{~kW} / \mathrm{m}^{2}$, corresponding to $110 \mathrm{MW}$ transferred to the first wall of the tokamak (other than $400 \mathrm{MW}$ neutrons which are accounted for as volumetric heating of $665 \mathrm{~kW} / \mathrm{m}^{2}$ and other than the divertor heat load). This upper estimate is on the safe side as it implies

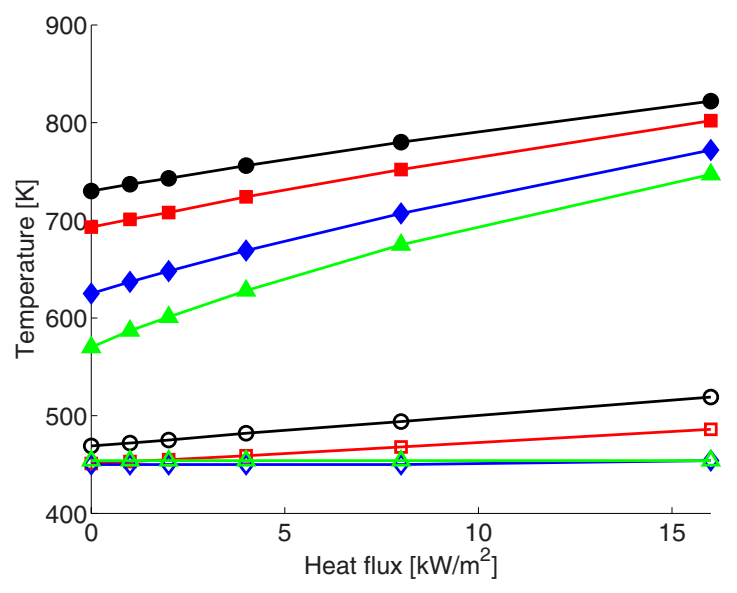

FIG. 2. (Color online) Maximum temperature as function of heat flux for various mirror thicknesses and radiation cooling vs active cooling. Solid symbols: radiation cooling, contoured symbols: active cooling. Mirror thickness: $(\bigcirc) 30 \mathrm{~mm},(\square) 20 \mathrm{~mm},(\diamond) 10 \mathrm{~mm}$, and $(\triangle) 5 \mathrm{~mm}$.

divertor heat loads below $100 \mathrm{MW}$. The upper four curves with solid symbols reveal the maximum temperatures of first mirrors with thicknesses from 5 to $30 \mathrm{~mm}$. In this scenario, the mirrors are assumed to be cooled by radiation and conduction alone. Obviously, the temperatures increase for larger radiation heat fluxes. It can be noted that thicker mirrors have larger maximum temperatures than thin mirrors. The reason is that the characteristic penetration depth of neutrons in stainless steel (SS316) is much larger than the mirror thickness, implying that only a small part of the streaming neutrons is absorbed in the mirror and that the $\gamma$ and neutron heating power is proportional to the mirror volume (or the thickness). The lower four curves show the corresponding results for actively cooled mirrors, leading to the same conclusion. As the backside is cooled to $433 \mathrm{~K}$, the maximum temperature is less sensitive to the plasma radiation heat load (although of course the active cooling demand increases with heat load).

The maximum temperature of the mirror is a function of material emissivity, especially for mirror cooling relying entirely on radiation and conduction. The sensitivity of the re-

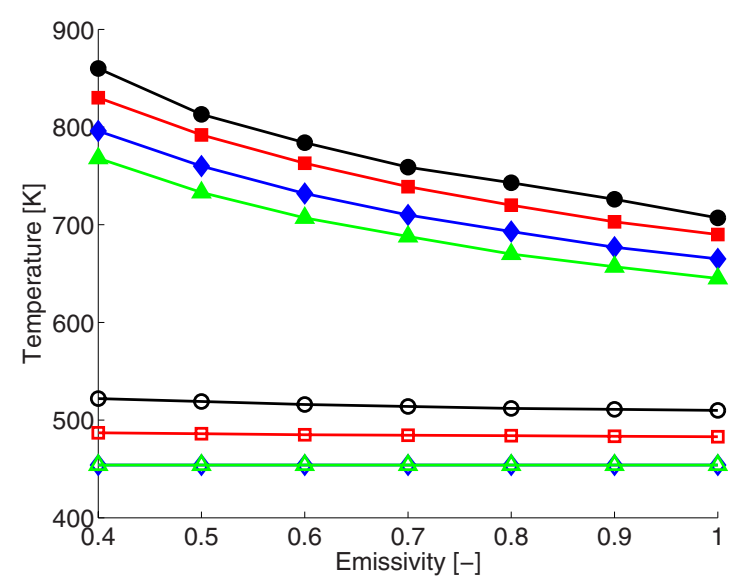

FIG. 3. (Color online) Maximum temperature as function of emissivity for various mirror thicknesses and radiation cooling vs active cooling. Solid symbols: radiation cooling, contoured symbols: active cooling. Mirror thickness: $(\bigcirc) 30 \mathrm{~mm},(\square) 20 \mathrm{~mm},(\diamond) 10 \mathrm{~mm}$, and $(\triangle) 5 \mathrm{~mm}$. 


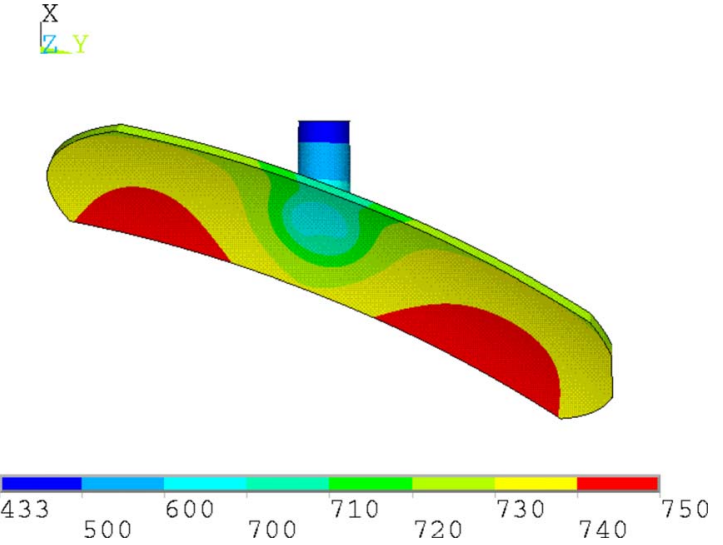

FIG. 4. (Color online) Temperature distribution (in kelvin) on HFS first mirror with $5 \mathrm{~mm}$ thickness under base line conditions.

sults to this parameter is addressed in Fig. 3. The parametric variation of the emissivity must be carried out since there is considerable spread in the data due to dependence of the emissivity on for example surface roughness, temperature, or coating. In fact, no code qualified values could be established yet. ${ }^{14}$ The smaller the emissivity, the larger the temperature levels become, and large emissivities are therefore beneficial for the mirror option without active cooling. For actively cooled mirrors, the emissivity is unimportant since the active cooling contribution is much larger than the radiation cooling contribution.

The thinner the mirror is, the smaller the maximum temperatures and the thermal gradients across the mirror thickness. Thin mirrors are clearly advantageous in this respect. However, the conclusion that thin mirrors are beneficial will have to be qualified since excessively thin mirrors are prone to thermal gradients present on the backside, as Fig. 4 illustrates in which the mirror thickness is set to $5 \mathrm{~mm}$. The temperatures are significantly lower in the support arm region due to the conduction heat sink it offers. A second lower bound on the mirror thickness arises from the difficulty to manufacture very thin mirrors ensuring the required quality.

As first estimate of the thermal deformation due to ther-

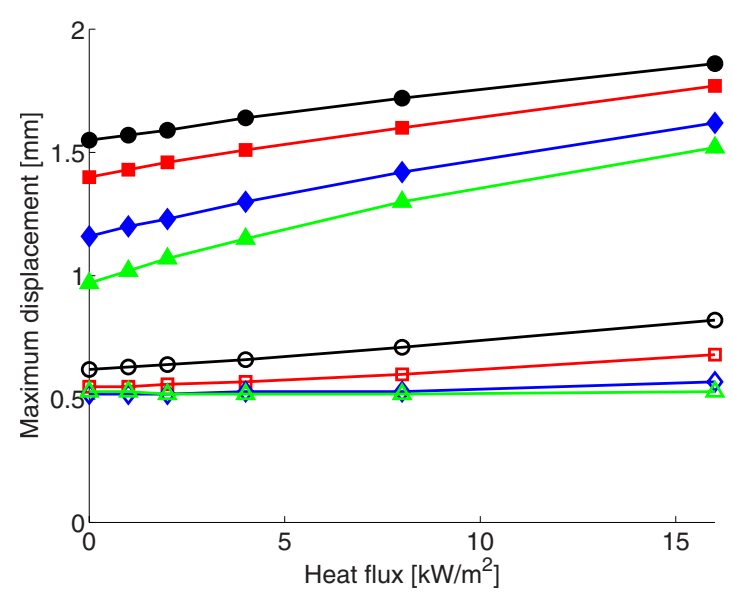

FIG. 5. (Color online) Maximum displacement as function of heat flux for various mirror thicknesses and radiation cooling vs active cooling. Solid symbols: radiation cooling, contoured symbols: active cooling. Mirror thickness: $(\bigcirc) 30 \mathrm{~mm},(\square) 20 \mathrm{~mm},(\diamond) 10 \mathrm{~mm}$, and $(\triangle) 5 \mathrm{~mm}$.

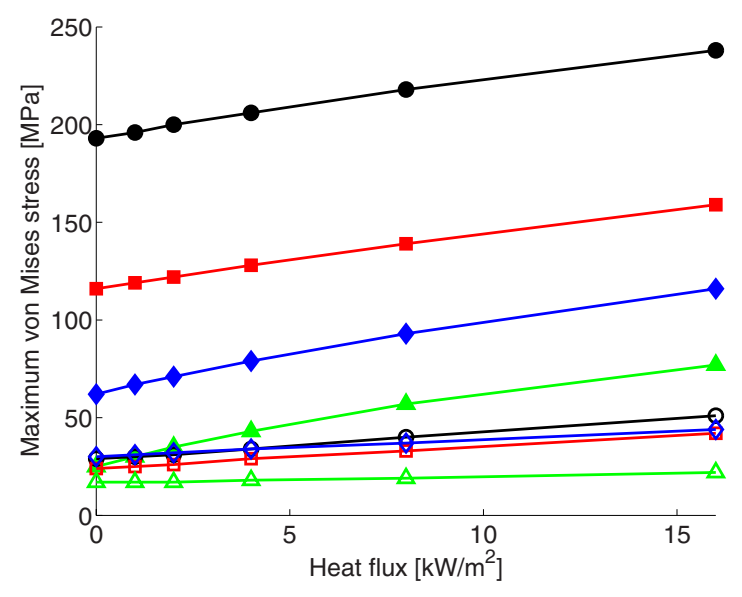

FIG. 6. (Color online) Maximum thermal von Mises stresses as function of heat flux for various mirror thicknesses and radiation cooling vs active cooling. Solid symbols: radiation cooling, contoured symbols: active cooling. Mirror thickness: $(\bigcirc) 30 \mathrm{~mm},(\square) 20 \mathrm{~mm},(\diamond) 10 \mathrm{~mm}$, and $(\triangle) 5 \mathrm{~mm}$.

mal strain, we use the maximum displacement vector magnitude which is defined for each point on the mirror surface between the burn condition and room temperature condition. This parameter is not sensitive to the direction of the displacement. Figure 5 demonstrates that the maximum displacement magnitude is on the order of 1-2 $\mathrm{mm}$ for radiation cooled mirrors and slightly larger than $0.5 \mathrm{~mm}$ for actively cooled mirrors. The thinner mirrors tend to be warped and displaced less than thicker mirrors. However, beam propagation modeling will be necessary to assess the impact of thermal deformation on the beam shape which in turn has impacts on the achievable accuracy of the inference of the fast ion velocity distribution function. The beam propagation modelling and therewith the uncertainty estimate will be addressed in a future study.

Lastly, the impact of mirror thickness on thermal von Mises stresses is studied in Fig. 6. The absolute levels can be changed by mirror design, but the impact of mirror thickness is clearly demonstrated: Thermal von Mises stresses increase with mirror thickness. Thinner mirrors will therefore have a larger safety margin against the regime of plastic deformation. Second, large thermal von Mises stresses can be remedied by active cooling. With the present mirror geometries, the thermal von Mises stresses in radiation cooled mirrors (without active cooling) larger than $10 \mathrm{~mm}$ are unacceptable, even for the lowest heat fluxes. Ultimately, the first mirrors will have to be designed against electromagnetic forces which are not included in the present work.

Future work will be dedicated to a detailed material selection, the characterization of propagation of the electromagnetic waves through the deformed quasioptics, the effect of the horizontal gap between the blankets, cooling system design, and stress modeling accounting for rounded edges and electromagnetic forces.

\section{ACKNOWLEDGMENTS}

This work, supported by the European Communities under the contract of Association between EURATOM / Ris $\varnothing$ DTU, was partly carried out within the framework of the 
European Fusion Development Agreement. The views and opinions expressed herein do not necessarily reflect those of the European Commission.

${ }^{1}$ H. Bindslev, J. A. Hoekzema, J. Egedal, J. A. Fessey, T. P. Hughes, and J. S. Machuzak, Phys. Rev. Lett. 83, 3206 (1999).

${ }^{2}$ H. Bindslev, S. K. Nielsen, L. Porte, J. A. Hoekzema, S. B. Korsholm, F. Meo, P. K. Michelsen, S. Michelsen, J. Oosterbeek, E. L. Tsakadze, E. Westerhof, and P. Woskov, Phys. Rev. Lett. 97, 205005 (2006).

${ }^{3}$ F. Meo, H. Bindslev, S. B. Korsholm, V. Furtula, F. Leuterer, F. Leipold, P. K. Michelsen, S. K. Nielsen, M. Salewski, J. Stober, D. Wagner, P. Woskov, the ECRH group at ASDEX, and the ASDEX Upgrade team, Rev. Sci. Instrum. 79, 10E501 (2008).

${ }^{4}$ F. Meo, H. Bindslev, S. Korsholm, E. Tsakadze, C. Walker, P. Woskov, and G. Vayakis, Rev. Sci. Instrum. 75, 3585 (2004).

${ }^{5}$ E. Tsakadze, H. Bindslev, S. Korsholm, A. Larsen, F. Meo, P. Michelsen, S. Michelsen, A. Nielsen, S. Nimb, B. Lauritzen, E. Nonbol, and N. Dubios, Fusion Sci. Technol. 53, 69 (2008).

${ }^{6}$ A. Donne, A. E. Costley, R. Barnsley, H. Bindslev, R. Boivin, G. Conway, R. Fisher, R. Giannella, H. Hartfuss, M. von Hellermann, E.
Hodgson, L. C. Ingesson, K. Itami, D. Johnson, Y. Kawano, T. Kondoh, A. Krasilnikov, Y. Kusama, A. Litnovsky, P. Lotte, P. Nielsen, T. Nishitani, F. Orsitto, B. J. Petersen, G. Razdobarin, J. Sanchez, M. Sasao, T. Sugie, G. Vayakis, V. Voitsenya, K. Vukolov, C. Walker, K. Young, and the ITPA Topical Group on Diagnostics, Nucl. Fusion 47, S337 (2007).

${ }^{7}$ A. Costley, T. Sugie, G. Vayakis, and C. Walker, Fusion Eng. Des. 74, 109 (2005).

${ }^{8}$ H. Hartfuss, R. König, and A. Werner, Plasma Phys. Controlled Fusion 48, R83 (2006).

${ }^{9}$ A. Litnovsky, V. Voitsenya, A. Costley, and A. Donne, Nucl. Fusion 47, 833 (2007).

${ }^{10}$ ITER Organization, Technical Report ITER Design Description Document No. 55 DDD 6 01-06-01 W 0.3, 2005.

${ }^{11}$ K. Takahashi, N. Kobayashi, and K. Kasugai, A. Sakamoto, Fusion Eng. Des. 81, 281 (2006).

${ }^{12}$ N. Kobayashi, G. Bosia, and B. Petzold, Fusion Eng. Des. 53, 475 (2001).

${ }^{13}$ Technical Report No. LA-UR-03-1987, Los Alamos National Laboratory, 2003.

${ }^{14}$ ITER Organization, Technical Report ITER Document No. S 74 MA 2, 2007 